\title{
Occupational change and wage inequality: European Jobs Monitor 2017
}

ENRIQUE FERNÁNDEZ-MACÍAS, JOHN HURLEY and JOSÉ MARÍA ARRANZ-MUÑOZ

Eurofound, Dublin, 2017, pp. 90

Book review by PREDRAG BEJAKOVIĆ*

doi: 10.3326/pse.41.3.6

* Received: July 22, 2017

Accepted: July 25, 2017

Predrag BEJAKOVIĆ, Ph.D.

Institute of Public Finance, Smičiklasova 21, 10000 Zagreb, Croatia

e-mail: predrag@ijf.hr

ORCID iD: 0000-0002-4164-8220 
There is almost no need to underline the importance of employment and income equality in a society. However, there is a serious lack of surveys on the relations between occupational change and wage inequality. Enrique Fernandez-Macias and John Hurley from Eurofound in Dublin, and Jose Maria Arranz-Munoz from Universidad de Alcalá have successfully addressed this demanding task in the publication Occupational change and wage inequality: European Jobs Monitor 2017'. This analysis is an outcome of the Eurofound project entitled European Jobs Monitor.

In the first chapter, Labour market context, the authors explain how in 2016, employment levels in the EU made up for all the serious net losses registered during the global economic crisis. While in 2008 there were more than 223 million people employed in the EU, according to the Labour Force Survey in 2016223.6 million were in work. Between mid-2013 and mid-2016, in the EU 8 million net new jobs were created. As the structure of employment has changed significantly, this report tries to encapsulate these changes and then using the "jobs-based approach" to explain further details on diversities in the world of work, regarding sectors, gender, working time and/or contractual status. Moreover, employment growth outstripped the increase in GDP. There are two possible explanations why employment growth surpassed output growth. The first one is that companies may hesitate to hire at the beginning of a recovery until the conditions are estimated stable. In that way, a noteworthy part of later job growth is caused by delaying decisions to hire. The second explanation may be consumption-driven rather than motivated by increase in investment and/or exports. This has led to solid job creation in the services sector, which is usually more labour intensive and more dependent on changes in consumption. Such employment growth is less related to any increase in productivity, which could explain the relatively modest GDP growth.

In all member states (MS), the increased number of employees in the service sector has followed the reduction of employees in manufacturing and construction. Thus, the service sector now represents $71 \%$ of EU employment. In some countries like Austria, Germany and Hungary - the shift to services has been moderate, but in $13 \mathrm{MS}$, it has been very sharp. Next to the changes of shares of particular economic sectors in total employment, there are also some other salient differences in employment. This is primarily linked to an increased share of older workers, caused by a decrease of youth participation and employment, increased motivation for staying longer in the labour force and reduced possibilities for early retirement. Moreover, there is an obvious increase of part-time work, mostly caused by a replacement of - mostly male - fulltime employment by new forms of part-time employment, where both genders participate more or less equally. Further characteristics of the modern world of work are a diminishing gender employment gap and an increasing share of employment in white-collar occupations that require

\footnotetext{
${ }^{1}$ Available at: <https://www.eurofound.europa.eu/publications/report/2017/occupational-change-and-wageinequality-european-jobs-monitor-2017>.
} 
high educational attainments and skill levels, like managers, professionals and associate professionals. Such changes reflect modes of labour demand biased towards the service sector, higher skills and the normal upgrading of the workforce. This happens as older workers withdraw from the labour market due to retirement and younger persons with higher average educational and qualification attainment enter it.

Regarding the spatial distribution on growth of employment, there were positive trends in Germany and the UK, where between the second quarter 2008 and the same quarter of 2016, 2.9 and 2 million new jobs were created. On the other hand, over the same period, Spain lost more than 2.3 million jobs, Greece and Romania both lost more than 900 thousand jobs and Portugal over 500 thousand. In the case of Greece, Portugal and Spain, the severity of the economic crisis and the effects of the implemented political measures explain much of the job reduction.

The employment shifts in the EU during the period 2011-2016 are the topic of the second chapter. At first, overall trends in the EU are presented, with different patterns of change in particular MS. The observed period has been divided into two parts. The earlier part from mid-2011 to mid-2013 is characterised by employment decline caused by economic recession, the global financial and the sovereign debt crisis. Because of the global financial crisis (from 2008 to mid-2013), job losses were around 6.2 million. The second period is characterised by significant employment growth, so around 8 million new jobs were created. Dividing mentioned trends by income quintiles, new employment since 2013 has been equally distributed through the whole wage and salary range, with only a slight slant towards the top quintile. During the period 2013-2016, employment increased in each of the job-wage quintiles. Employment growth was more pronounced in the top quintile, followed by the lowest and mid-high quintiles, while the feeblest growth was documented in the middle and mid-low quintiles.

It is necessary to recall that the number of well-paid jobs have increased even during the crisis period from 2008 to 2010, and contributed strongly in all periods to total growth in employment. On the other side, there is a relative weak employment increase in the mid-low and middle quintiles. The main driver of employment change is technology. Its crucial outcome is to raise the demand for skilled labour force in post-industrial societies at the expense of less skilled labour. There are also some other influences like employment protection legislation and minimum wage legislation, labour taxation, collective representation and differences in welfare regimes. In many countries, employment trends do not follow any obvious path, are irregular or are some mix of the different patterns. This is partly due to the short period covered by the analysis, because structural changes are usually obvious only after three or five years.

In many countries (including Croatia), there are intensive discussions on the enrolment policies and occupations that young people should select. Of course, edu- 
cation cannot be adjusted only to current needs on the labour market, because current students are learning and obtaining skills that will enable their employability and labour for next forty or even more years. However, without doubt there is a need for adjustments of the need on the labour market and output of the education system. For such adjustment, the authors present top twelve fastest-growing and fastest-declining large-employing jobs. In general, trends in both the fastestgrowing and fastest diminishing jobs are probably going to contribute even more to employment polarisation, characterised with significant demand for some occupations and an alarmingly reduced demand for others.

In the third chapter, employment changes are presented according to the most important sectoral aggregations, employment positions and worker characteristics. The goal is to show how the service change defined in the quintile structure interconnects with development of other dimensions of the labour market, like the growing share of the service sector in total employment, the rapid increase of nonstandard (primarily part-time) work and the growing share of female employment. The long-term shift to employment in the service sector speeded up during the period after the 2008 economic crisis. At that time, there was an obvious strong adverse employment impact of the crisis on non-service sectors, primarily manufacturing and construction. In the EU in the period between 2008 and 2013, despite the total net loss of 7.5 million jobs, employment in the service sector actually grew. As regards construction and manufacturing, both sectors continued to reduce employment through to 2013. After that, there has been growth in both sectors, although only slight in construction, but more noticeable in manufacturing. In both sectors, net new employment possibilities have been biased to betterpaid jobs. Furthermore, manufacturing employment in the EU has been shifting from the old MS to eastern European MS that became EU members after 2004.

One consequence of the crisis was the lowering of the share of European workers among full-time permanent employees, in the so called core employment status. Since the recovery in EU labour markets, there has been only modest increase of net new employment in core employment status. On the other hand, there was a constant enlargement of part-time work, so this form of employment is the main vector of destandardisation. Furthermore, next to working part-time, there are many who are on temporary contracts, self-employed or some combination of these categories. As labour market conditions improved since 2013, the share of core employment has stabilised in the majority of MS. Core employment status has accounted for the biggest share of employment growth in all quintiles, though only in top well-paid quintile jobs does it account for the majority of net new employment. Part-time employment grows across all quintiles, while self-employment is mostly present in the groups of high paid jobs of experts in the education, health, and legal and accounting services as well as by ICT professionals.

The second part of the book entitled Wage inequality from an occupational perspective contains five shorter chapters. The fourth chapter is dedicated to back- 
ground and methodology, where the authors remind us that in the past two or three decades, wage inequalities have been growing in many developed economies. There are of course important exceptions and variations in the extent and timing of the changes in different economies. They evaluate to what extent wages are an essential explanatory factor for wage inequalities in France, Germany, Italy, Netherlands, Poland, Romania, Spain, Sweden and UK. Furthermore, as this study covers European countries with different institutional and economic models, the focus is on differences that occupations have in the distribution of wages. Finally, the attention is oriented towards the time dimension, having in mind changes in the role of occupational wages during the recent economic crisis.

Static analysis of the role of occupations in determining the wage dispersal is presented in the fifth chapter. In classical economics literature, wages mostly reflect productivity differentials among individuals, and occupations are almost fully neglected. However, there are reasons for thinking that occupations could be linked to wage differentials without having a direct impact on wage determination. Various preferences and labour market discrimination caused by cultural and social factors can produce a systematic over- or under-representation of particular social groups in specific occupations. This may affect the status, influence and social power associated with the occupations and may end up strengthening the inequality that initially generated the segregation.

When the data are grouped by occupations, the total variance of wages in a country can be divided into the variance from between-group differentials and the variance that results from within-group variability. Between-job differentials explain about $50 \%$ of the total variance, while within-job variabilities account for the other half, but there are significant variations across the countries. The reasons why occupations represent such a significant factor in wage inequality are differences in human capital, but there is also impact of the characteristic of employment contracts and skill levels. Furthermore, in the Netherlands and to a lesser magnitude in Sweden and the UK, one should not neglect occupational segregation by gender and age as important causes of wage inequality. Unfortunately, the available data did not allow the direct evaluation of the role of occupational mechanisms, but the authors provide possible explanations for some of the observed discrepancy in wages.

Occupational wage differentials across European institutional models are examined in chapter six. The authors re-evaluate the levels of overall wage inequality, the variance of wages that can be clarified by occupational differentials. They try to find the connection between occupational differentials and human capital, age, gender and social classes. Of the observed countries, the most unequal wage distribution is that of Romania (Gini overall wage inequality is 39.02), followed by the UK and Poland, and then Italy and Spain as examples of southern Europe model. On the other side, inequality is lower in France, Germany and the Netherlands, the countries from so called continental or corporate model, and finally the 
lowest level of wage inequality is recorded in Sweden (Gini overall wage inequality is 18.91), as an example of Scandinavian model. Next to the presentation of the situation in a particular country, the authors underline that there is an outstanding similarity in occupational wages in observed MS. When a particular job is very well paid in one country, it tends to be very well paid in all other countries. Thus, regardless of the inequality in the distribution of wages in a particular country, everywhere there is the same the proportion of such inequality within occupations (approximately between $50 \%$ and $60 \%$ ), while the remaining $40-50 \%$ of inequality results from occupational wage differentials. It is also interesting that the big differences in wage-setting institutions and mechanisms (coordinated by markets or collective agreements, with various levels of centralisation of collective negotiation and/or coverage of collective agreements, or with different systems of occupational licensing) at the end have very similar outcomes.

Occupations and the evolution of wage inequality in Europe are examined in the seventh chapter. According to various surveys, it is not fully clear if the recent increase in wage inequality was caused by more pronounced occupational wage differentials, or whether they remained mostly stable. While some authors found a decreasing role of occupations in wage inequality, some others had completely the opposite results. These inconsistencies are probably caused by the methodological challenges in the evaluation of the significance of occupations in wage inequality over long periods. According to various methodological approaches (ANOVA test and Theil decomposition of wage inequality), the latest data for the past decade show a stable or slightly increasing impact of occupational wage differentials in structuring wage inequality in Europe. Changes in wage inequality within jobs or occupations cause total inequality, not changes in occupational wage differentials or in occupational employment shares. In that way, changes in occupational structures (mentioned job upgrading or polarisation) do not have significant consequences on the trends of wage inequality.

In the final chapter eight, the authors provide a conclusion, reiterating the finding that occupations are an important structuring factor of wage inequalities in all analysed European countries. There were differences among observed countries in the way in which occupations influence wage inequalities. For instance, in some examples, there were big outliers in the distribution of wages that seemed unrelated to the occupational structure. In some countries, like the UK, occupational wage differentials seem to be strongly influenced by the nature of employment relations or forces in labour markets. On the other hand, in some other countries, like the Netherlands, occupational wage differentials are more related to mechanisms of occupational segregation by age, gender or other sociodemographic factors. The occupational structure provides a unifying support to wage distributions in Europe, with occupational wages accounting for a very similar part of overall wage inequality in all countries and occupational importance and ranking being very similar despite huge differences in wage inequality levels. The support is the same, but it is comparatively stressed in the observed countries ac- 
cording to the total level of wage inequality, connected with institutional differences in bargaining and educational systems as well as some other factors.

This relatively short book is unbelievably rich in details and it should be an object of interest for all readers interested in the labour market, inequality and the development of occupation structure. The reader can only praise the authors for their efforts and the clear explanation of this complex topic. One can only hope that the future researches on the same or similar subject can include data from more countries (including Croatia) and for a longer period. 